\title{
A humanização como dimensão pública das políticas de saúde
}

\author{
Humanization as a public dimension \\ of the policies in the health system
}

Regina Benevides 1

Eduardo Passos 2

\footnotetext{
1 Departamento de Psicologia, Universidade Federal Fluminense. Campus do Gragoatá, Bloco 0, 30 andar, 24000-000, Niterói RJ. rebenevi@terra.com.br 2 Departamento de Psicologia, Universidade Federal Fluminense.
}

Abstract As long as it is assumed that humanization is a fundamental aspect regarding the health policies it is demanding that its concept be revised and criticized so changes in the models of assistance and management can be performed. Such urge is presented not only because the concept has been trivialized, but also by the fragmentation of the practices connected to different programs of humanization of the health system. It is the same problem in a double inscription theoretical/practical, so the need to face the task of redefining the concept of humanization as well as the construction of public and transversal policies of humanization of/and in the health system. This second aspect points out to the need of a debate on the public dimension of the health policies and its relation with the Government. This paper intents, supported by Foucault's analysis of power, to exam the concept of humanization in a more wide scenario showing the relationship of the Government with the public policies as concrete experiences, assuring that there is no way of guaranteeing a National Policy of Humanization of $\mathrm{H}$ ealth without confronting with the concept of humanism in the contemporary world. In the 20th Century, the idea was strongly stressed by an anti-humanistic critic and the task we face now is not easy and has to be carried out so we can redirect ourselves.

Key words Public policies, H umanization, Single H ealth System, Anti-humanism
Resumo No momento em que se assume a humanização como aspecto fundamental nas políticas de saúde urge que o concei to de humanização seja reavaliado e criticado para que possa efetuarse como mudança nos modelos de aten ção e de gestão. Tal urgência se configura pela banalização com que o tema vem sendo tratado, assim como pela fragmentação das práticas ligadas a programas de humanização. Trata-se de um mesmo problema em uma dupla inscrição teórico-prática, daí a necessidade de redefinição do conceito de humanização, bem como dos modos de construção de uma política pública e transversal de humanização da/na saúde. Este segundo aspecto apontou para o debate sobre a dimensão pública das políticas de saúde em sua relação com o Estado. 0 texto se dedica, orientado pela análise foucaultiana do poder, a examinar o conceito de humanização na relação do Estado com as políticas públicas como experiência concreta, afirmando que não há como garantir uma política nacional de humanização da saúde sem que se confronte com o tema do humanismo no contemporâneo. Esta tarefa não é simples, já que o pensamento no século 20 foi fortemente marcado por uma crítica anti-humanista que deve agora ser retomada para que possamos nos reposicionar.

Palavras-chave Políticas públicas, H umanização, Sistema Ú nico de Saúde, Anti-humanismo 


\section{Introdução}

0 debate a que nos propomos neste artigo está apoiado nas experiências desenvolvidas nos anos de 2003/2004, quando nos integramos à equipe da Secretaria Executiva (SE) do M inistério da Saúde (M S), como consultor e como Diretora de Programa da SE coordenando a "Política N acional de Humanização da atenção e da gestão na saúde" (PNH). Tais experiências dizem respeito a um cenário que a partir de 2005 se altera com a mudança na formulação e condução das políticas de saúde no M S. No momento em que escrevemos o presente texto acompanhamos com atenção os desdobramentos destas mudanças para saber se os princípios construídos nestas experimentações poderão reverberar nas novas configurações da máquina do Estado

\section{0 que pode uma política pública ou o tema do poder}

No início de 2003, enfrentamos um debate no M S defendendo a priorização do tema da humanização como aspecto fundamental a ser contemplado nas políticas públicas de saúde. 0 debate se fazia a partir da tensão entre concepções diferentes. Havia escolhas, de um lado, que visavam aos "focos e resultados dos programas" e, de outro, que problematizavam os processos de produção de saúde e de sujeitos, no plano mais amplo da alteração de modelos de atenção e de gestão. N este contexto, apresentava-se para nós não só um desafio, mas principalmente a urgência de reavaliar conceitos e práticas nomeadas como humanizadas. Identificada a movimentos religiosos, filantrópicos ou paternalistas, a humanização era menosprezada por grande parte dos gestores, ridicularizada por trabalhadores e demandada pelos usuários.

0 debate ia se montando em torno das condições precarizadas de trabalho, das dificuldades de pactuação das diferentes esferas do SUS, do descuido e da falta de compromisso na assistência ao usuário dos serviços de saúde. 0 diagnóstico ratificava a complexidade da tarefa de se construir de modo eficaz um sistema público que garantisse acesso universal, equânime e integral a todos os cidadãos brasileiros.

Não restava dúvida: o SUS é uma conquista nascida das lutas pela democracia no país que em 1988 ganham estatuto constitucional. Ga- rantir o "caráter constituinte" do SUS, impõe que possamos identificar os problemas contemporâneos que se dão na relação entre Estado e as políticas públicas. É esta relação que queremos problematizar neste momento que 0 projeto de uma Política Nacional de Humanização retoma o que está na base da reforma da saúde do porte daquela que resultou na criação do SUS.

Nos primeiros passos que demos imediatamente nos confrontamos com outro aspecto presente no âmbito do que se nomeava como programas de humanização: havia projetos, atividades, propostas, mas em todos era evidente o caráter fragmentado e separado dessas iniciativas não só na relação de baixa horizontalidade que se verificava entre elas, mas também no modo vertical como elas se organizavam dentro do MS e do SUS. Tínhamos, então, um duplo problema: seja o da banalização do tema da humanização, seja o da fragmentação das práticas ligadas a diferentes programas de humanização da saúde. $\mathrm{N}$ a verdade, trata-se de um mesmo problema em uma dupla inscrição teórico-prática, daí a necessidade de enfrentarmos a tarefa de redefinição do conceito de humanização, bem como dos modos de construção de uma política pública e transversal de humanização da/na saúde.

Diante deste duplo problema, a SE do M S propôs a criação da PNH. Como política, a humanização deveria traduzir princípios e modos de operar no conjunto das relações entre todos que constituem o SU S. Era principalmente o modo coletivo e co-gestivo de produção de saúde e de sujeitos implicados nesta produção que deveria orientar a construção da PN H como política pública.

Esta orientação imporia mudanças no modelo de atenção dos usuários e da gestão dos processos de trabalho. 0 projeto da PNH foi afirmar a saúde não como valor de troca, mas como valor de uso (Campos, 2000), o que faz com que se altere o padrão de atenção no sentido da ênfase no vínculo com os usuários, garantindo seus direitos. Estimulava-se o protagonismo dos atores do sistema de saúde fosse pela sua ação de controle social, fosse pelo fomento de mecanismos de co-gestão. Garantir melhores condições para os trabalhadores e gestores realizarem seu trabalho foi outra direção da PNH. A humanização como política pública deveria criar espaços de construção e troca de saberes, investindo nos modos de trabaIhar em equipe. Isto supõe, é claro, lidar com 
necessidades, desejos e interesses destes diferentes atores.

A humanização se apresentava para nós como estratégia de interferência no processo de produção de saúde levando em conta que sujeitos, quando mobilizados, são capazes de transformar realidades transformando-se a si próprios neste mesmo processo. Investíamos na produção de um novo tipo de interação entre os sujeitos que constituem os sistemas de saúde, retomando a perspectiva de rede descentralizada e co-responsável que está na base do SUS. U ma rede comprometida com a defesa da vida, rede humanizada porque construindo permanente e solidariamente laços de cidadania.

Humanizar a atenção e a gestão em saúde no SUS se apresentava como meio para a qualificação das práticas de saúde: acesso com acoIhimento; atenção integral e equânime com responsabilização e vínculo; valorização dos trabalhadores e usuários com avanço na democratização da gestão eno controle social participativo.

Com estas direções definimos os seguintes princípios norteadores (Brasil, 2004): 1) valorização da dimensão subjetiva e social em todas as práticas de atenção e gestão no SUS, fortalecendo o compromisso com os direitos do cidadão, destacando-se o respeito às questões de gênero, etnia, raça, orientação sexual e às populações específicas (índios, quilombolas, ribeirinhos, assentados, etc.); 2) fortalecimento de trabalho em equipe multiprofissional, fomentando a transversal idade e a grupalidade; 3) apoio à construção de redes cooperativas, solidárias e comprometidas com a produção de saúde e com a produção de sujeitos; 4) construção de autonomia e protagonismo de sujeitos e coletivos implicados na rede do SUS; 5) co-responsabilidade desses sujeitos nos processos de gestão e de atenção; 6) fortalecimento do controle social com caráter participativo em todas as instâncias gestoras do SU S; 7) compromisso com a democratização das relações de trabalho e valorização dos profissionais de saúde, estimulando processos de educação permanente.

Pretendemos neste texto nos dedicar à tarefa de inserir o conceito de humanização na sua relação com o tema do Estado moderno. Não há para nós como garantir a aposta numa Política $\mathrm{N}$ acional de Humanização sem que nos confrontemos com o tema do humanismo no contemporâneo. Esta tarefa não é simples, já que o pensamento no século 20 foi fortemente marcado por uma crítica anti-humanista que devemos agora retomar para que possamos nos reposicionar.

A discussão da humanização no campo da saúde não pode se fazer sem que consideremos a maneira como o tema está intrinsecamente ligado ao processo de constituição do SUS no Brasil. Como sabemos, o SUS é o resultado de lutas pela redemocratização da sociedade brasileira que aconteciam em meio a movimentos de resistência à ditadura militar. No campo da saúde, essa resistência se exprimiu no M ovimento da Reforma Sanitária a partir do qual foram formulados os princípios de universalidade, eqüidade e integralidade da saúde na Constituição de 1988 como direito de qualquer cidadão e como dever do Estado. Os anos 60, 70 e 80, no Brasil, foram marcados por essas lutas que impunham não só a recolocação das funções e deveres do Estado, como também, os direitos dos homens. Todo um experimentalismo político caracteriza esses momentos de efervescência que na América Latina se orquestravam na forma geral da resistência ao autoritarismo de Estado. Há, nesses anos, um debate que acompanha as experimentações políticas em curso que precisamos resgatar na sua potência de problematização do poder. A final de contas, trata-se mesmo de avaliar os poderes instituídos e as resistências-instituintes de novos modos de viver e, mais especificamente, de lidar com o tema da saúde.

\section{A analítica do poder e as artes de governar: as contribuições de Michel Foucault}

Nos anos 70, podemos dizer que experimentamos mudanças das concepções do poder em práticas concretas discursivas e não discursivas. Essas mudanças estão presentes nas teses de M ichel Foucault que se dedica à construção de uma analítica do poder produzindo efeitos de desestabilização nas formulações acerca do tema. É importante lembrar que em maio de 1973 Foucault proferiu um conjunto de cinco conferências na PUC-Rio (Foucault, 1996). Essas conferências foram posteriormente publicadas e anteci pavam entre nós as teses genealógicas que em 1975 apareceriam no livro Vigiar epunir (Foucault, 1977).

Essa fase do pensamento foucaultiano, conhecida como período genealógico, caracteriza-se, sobretudo, por um método de acoplamento do conhecimento com as memórias locais, 
que permite a constituição de um saber histórico das lutas e a utilização deste saber nas táticas atuais (Foucault, 1979a). São, antes de tudo, anticiências no dizer de Foucault, insurreição dos saberes contra "os efeitos de poder central izadores que estão ligados à instituição". Para ele, a questão de todas as genealogias é a do poder: quais seus mecanismos, efeitos, relações e dispositivos que se exercem nos diferentes domínios da sociedade e com extensões tão variadas.

M ais tarde indicará que o método genealógico realiza sempre uma "ontologia histórica de nós mesmos" (Foucault, 2000), o que faz deste método a preparação de saberes que argúem o que somos, o que sentimos, o que cremos, desestabilizando o instituído para fazer aparecer as forças históricas do processo de sua institucionalização. A genealogia, neste sentido, éum método crítico por excelência que mantém ace so este ímpeto emancipatório próprio da modernidade em confronto constante com o já dado (Passos \& Benevides, 2001).

É com esta direção que queremos seguir em nossa tarefa de pensar a posição e importância conferida ao Estado na definição do plano do poder. Sendo nosso objetivo neste trabalho problematizar a humanização como política de Estado, parece-nos indispensável o esforço teórico de retomar as teses genealógicas de Foucault para melhor compreender a sintonia entre a emergência do Estado representativo moderno e uma certa concepção de homem que sustenta grande parte das propostas de humanização na saúde.

Em se tratando do tema do poder na perspectiva foucaultiana é menos apropriado falar em campo do que em um plano do poder. Tal distinção por nós anteriormente trabalhada (Benevides \& Passos, 2000) aponta para as diferenças entre os conceitos no que cada um deles se refere, seja ao domínio da realidade constituída (campo), seja em relação ao plano de constituição dessa realidade (plano). A tese tradicional é que a política se organiza como um campo que tem no centro a máquina do Estado da qual emanam os projetos de governo eas políticas públicas. A série, portanto, aqui, se faz no sentido descendente Estado-governo-política pública.

Foucault, na década de 70, propõe um conceito que subverte esta série tradicional que coloca o Estado como o locus de emanação do poder: trata-se do conceito de governamentalidade. 0 autor (Foucault, 1979c) destaca que entre o século 16 e o final do século 18 desenvolve-se uma série de tratados sobre a arte de governar. Como governar, como fazer para ser o melhor governante? Tais são as questões que emergem num contexto de instauração dos grandes Estados territoriais e de uma preocupação com a concentração estatal, mas também indicando movimento de dispersão e dissidência religiosa, como foi o caso da Reforma e da ContraReforma. É mesmo uma "problemática geral do governo em geral" (1979c) que se coloca como tema.

$M$ as Foucault, pesquisador dos textos menores, não se atém ao que na época era tomado como o discurso sobre o governar, tal como apresentado em 0 príncipe de M aquiavel. Ele destaca a existência de uma literatura antimaquiavélica entre o século 16 e o início do século 19 , que aponta para uma importante construção da arte de governar que desenhará e sustentará o Estado moderno.

0 que 0 autor propõe é o contraste entre duas tecnologias do poder que no século 16 se rivalizam. É a modulação de uma sociedade tradicional marcada por um diagrama de poder soberano para a sociedade moderna dita disciplinar. No primeiro diagrama, vemos um modo de governar caracterizado pela exterioridade, pela transcendência do príncipe em relação ao seu principado que ele recebe por herança, por aquisição ou por conquista e com o qual mantém laços por tratados, por violência. Decidir a morte ou deixar viver, eis a fórmula como a violência soberana se exercia na sociedade pré-moderna. 0 objetivo do exercício do poder é, conseqüentemente, o de reforçar e proteger este principado, entendido não como o conjunto constituído pelos súditos e o território... mas como [a] relação do príncipe com o que ele possui (Foucault, 1979c). Esta doutrina do príncipe ou a teoria jurídica do soberano marca uma descontinuidade entre o poder do governante e as outras formas de poder. Ação descendente e de exterioridade, transcendente e descontínua, o poder se exerce em sentido único, como habilidade em conservar o principado, custe o custar.

Essas são as premissas de M aquiavel em seu trabalho de aconselhamento do príncipe. 0 que Foucault diz, contrastando maquiavelismo e antimaquiavelismo, é que a modernidade política já não podia encontrar apoio em um diagrama de poder soberano.

Um outro diagrama se apresenta, segundo a expressão de Foucault, como uma arte de governar. E qual é a diferença entre o governo do 
soberano e esta arte que governa sob um regime que não é mais o do príncipe? Foucault destaca que no século 16 o governo começa a tomar como alvo não mais um território com seus súditos, mas um conjunto heterogêneo de "coisas". A diferença, portanto, se dá sobre o que se exerce e como se exerce o poder. É uma nova incidência do poder, novos alvos, e, portanto, uma nova visibilidade e dizibilidade que se anuncia no século 16. Fala-se neste momento do governo da casa, das almas, das crianças, da família.

Qual é, então, o lugar do Estado moderno na composição do plano do poder? A questão que Foucault quer, sobretudo, destacar é a dimensão do governo relativa ao Estado, isto é, a dimensão política do governo. E por que este destaque quando já não pensamos mais numa centralidade e sim numa dispersão do poder no plano das artes de governar? Qual o sentido de se colocar em questão a função centralizadora do Estado e, conseqüentemente, este sentido descendente da série Estado-governo-política pública? $\mathrm{N}$ a pesquisa acerca da "governamentalidade", partir do tema do Estado, figura macropolítica, éa estratégia escolhida para destituí-lo de qualquer primado na teoria política. $M$ as superar o Estado territorial é necessariamente substituí-lo por uma outra figura central de Estado? Como na modernidade a arte de governar em sua multifocalidade se relaciona com a pretensa centralidade política do Estado?

0 que Foucault está indicando é, numa torção da teoria política tradicional, que o lugar do poder se desloca na modernidade no que diz respeito a seu alvo e a seu modo de operar. A transcendência e a uniformidade do poder político soberano são substituídas, nas artes de governar a partir do século 16, pela multiplicidade dos exercícios de poder e pela sua imanência nos diferentes objetos ou "coisas" governadas. Eis aí uma nova topologia política, pois entre o foco de emanação do poder e seu ponto de incidência não há mais a distância que caracterizava o exercício soberano. Entre o príncipe e o território com seus habitantes há uma relação de exterioridade ou transcendência, diferente do que se afirma no século 16 acerca da inseparabilidade entre os diversos domínios do governo. Governar a nação, a família ea si mesmo são, doravante, exercícios que se realizam num mesmo plano de imanência do poder, de tal maneira que não há mais aquela distância entre quem exerce o poder e quem o sofre. A imanência desse plano na modernidade faz com que os termos ativo e passivo se distingam, mas não mais se separem, compondo um regime de poder cuja palavra de ordem se enuncia numa voz reflexiva: governa-se, governe-se. 0 poder assujeita na justa medida em que subjetiva. Assujeitar e subjetivar são, portanto, ações distintas porém inseparáveis no exercício do poder na modernidade.

Pesquisando as artes de governar, Foucault destaca a existência de três tipos de governo: 0 governo de si (domínio da moral), a arte de governar uma família ou a população (domínio da economia), e a ciência de bem governar o Estado (domínio da política). M as, o importante éa característica contínua e em mão dupla, indo tanto no sentido ascendente quanto descendente, das artes de governar. 0 sentido ascendente aponta para o fato de que "aquele que quer poder governar o Estado deve primeiro saber se governar, governar sua família, seus bens, seu patrimônio". Já o sentido descendente indica que quando o Estado é bem governado, os pais de família sabem como governar suas famílias, seus bens, seu patrimônio e por sua vez os indivíduos se comportam como devem (Foucault, 1979c).

Percebe-se o caráter multivetorializado do exercício do poder que, mesmo em sua relação com o Estado, não tem mais uma fonte e um objeto único de incidência privilegiados. 0 que Foucault chama de governamentalidade diz respeito ao "desbloqueio" das artes de governar "coisas", que entre os séculos 16 e 18 estavam ainda marcadas pelo modelo da família. A família como modelo de governo desaparece, reaparecendo não mais nesta condição mas como segmento ou instrumento privilegiado para o governo da população. É no século 18, portanto, que a preocupação com o controle da população realiza este desbloqueio das artes de governar, criando as condições para uma ação ampliada de governo que Foucault designa por "governamentalidade".

\section{A máquina do Estado e suas linhas}

Na modernidade, portanto, os níveis de governo se encaixam: o governo político, o econômico e o moral se dobram uns sobre os outros gerando esta arquitetônica complexa, multivetorializada e contínua. 0 Estado não tem mais a primazia de foco ou de centro do poder, no entanto ele permanece como um dos pontos de referência na constituição da governamentalidade: plano multifocalizado no qual Estado, fa- 
mília esi mesmo se apresentam como três referências para as práticas de governo. Quanto ao governo político, inverte-se a série que partia da centralidade do Estado. Temos agora uma outra série que considera o Estado uma das referências para as artes de governar. Neste caso, a série se altera para governo-Estado-política pública entendendo-se, assim, que é em um regime moderno de governamental idade que 0 governo político se faz na referência ao Estado em sua relação com a dimensão pública das políticas.

\section{Política (pública) de humanização: por um novo humanismo}

Quando chegamos no M inistério da Saúde nos deparamos com a máquina do Estado com seu intrincado poder ali expresso em programas, projetos, burocracias, instâncias e esferas de governo político. A complexidade desta máquina faz de seu interior um mundo que tende a nos atrair e capturar. Percebíamos que o Estado, embora não sendo a fonte de onde emanam as linhas de capilarização do poder, tende a absorvê-las, interiorizando-as. Contudo, a experiência no MS também nos indicava que estas linhas não dobram apenas para dentro. Há algo que resiste a esta interiorização, al go que insiste em sua exterioridade fazendo com que a máquina do Estado se abra para o que é o seu fora. Chamamos este fora de plano coletivo aí onde se constroem, de fato, políticas públicas. A PNH se propôs a operar neste limite entre a máquina do Estado e o plano coletivo, apostando que na série governo-Estado-políticas públicas, é este último termo que deve prevalecer na orientação das ações governamentais. A nosso ver, alterações da experiência coletiva é que podem gerar políticas públicas malgrado 0 movimento de interiorização da máquina de Estado. N a série governo-Estado-políticas públicas é o que se produz no plano do coletivo que garante o sentido público das políticas que também atravessam o Estado.

Esta, sem dúvida, foi a direção do movimento das políticas públicas de saúde que culminou no SUS. Com o conceito de saúde coletiva é a dimensão do público que é revigorada nas políticas de saúde. Não mais identificado a estatal, o público indica assim a dimensão do coletivo. Política pública, política dos coletivos. Saúde pública, saúde coletiva. Saúde de cada sujeito, saúde da população.
$M$ as, o desafio assumido a partir da década de 1970 pelos movimentos de mudança dos modelos de atenção e gestão nas práticas de saúde impunha tanto a redefinição do conceito de saúde, quanto a recolocação da importância dos atores implicados no processo de produção de saúde. Falar, portanto, de saúde pública ou saúde coletiva é falar também do protagonismo e da autonomia daqueles que, por muito tempo, se posicionavam como "pacientes" nas práticas de saúde, sejam os usuários dos serviços em sua paciência diante dos procedimentos de cuidado, sejam os trabalhadores el es mesmos, não menos passivos no exercício de seu mandato social. 0 que queremos ressaltar é que a força emancipatória na base do SUS só se sustenta quando tomamos como inseparáveis o processo de produção de saúde e o processo de produção de subjetividades protagonistas e autônomas que se engajam na reprodução e/ou na invenção dos modos de cuidar e de gerir os processos de trabalho no campo da saúde. N este sentido, é preciso avançar, como indica Gastão Wagner (Campos, 2000), a discussão no campo da saúde coletiva propondo esta relação entre produção de saúde e produção de sujeitos, entre atenção, gestão e subjetividade. Portanto, recolocar na agenda da saúde o tema da humanização é reativar o movimento constituinte do SUS.

0 criticismo moderno se apresenta, diante da crise do Antigo Regime, como experiência revolucionária, cujo ímpeto emancipatório do H umanismo impõe imediatamente uma reação contra-revolucionária. A dimensão crítica da modernidade se apresentava, portanto, como uma dupla face que coexiste por tensionamento: por um lado, uma força emancipatória que recusa toda transcendência como fundamento da experiência humana, por outro, uma retomada desta transcendência por uma manobra sofisticada associada à instauração do Estado moderno, Estado- $\mathrm{N}$ ação.

A tese de $\mathrm{H}$ ardt e $\mathrm{N}$ egri (2001) é de que a modernidade é a "afirmação dos poderes deste mundo, a descoberta do plano de imanência". A filosofia moderna impunha uma valorização da individualidade que encontra em si mesma sua fundação, sem a necessidade, doravante, de um fundamento transcendente (Deus, o soberano ou qualquer outra figura da lei transcendente). É a dignificação do humano, de seu mundo e de seu pensamento. $N$ ão é preciso um "para além" que dê sentido àquilo que a arte humana realiza. 
Mas se a modernidade tem uma dupla face, é porque seu conceito não é unitário e a crise logo se impõe na forma de uma reação contrarevolucionária que reinstaura a transcendência contra a potência da imanência. À força e ao desejo que pulsam como potência dos coletivos sobrevém uma figura cuja função é a de mediar toda experiência: é o Estado- $\mathrm{N}$ ação que tem a função de disciplinar, estabelecer e regular as relações entre os sujeitos formalmente livres. A liberdade, definida como experiência imediata dos coletivos, se submete neste instante às formas de mediação de uma nova transcendência.

O Estado é a forma da soberania moderna definida por um jogo de transcendência e representação completamente estranho ao ímpeto revolucionário moderno. 0 soberano moderno tem seu poder enraizado neste plano imanente das relações humanas. Daí a idéia de Estado representativo moderno que a um só tempo se propõe como garantia da expressão política das massas e se apresenta como a forma da alienação do poder daqueles que no Estado estariam representados. $N$ este sentido, se estabelece um contrato de associação e ao mesmo tempo um contrato de subjugação. Esta face contra-revolucionária da modernidade, sua face soberana, se assenta em uma concepção de contrato social que garante um acordo entre os indivíduos na medida em que a força e a vontade desses sejam desenvolvidos e sublimados para a construção de uma vontade geral e que esta vontade geral provinda da alienação das vontades isoladas garanta a soberania do Estado.

Temos, então, a situação paradoxal de uma soberania que, se tradicionalmente se definia como poder de um, na modernidade se assenta na alienação do poder das massas à autoridade do Estado. A vontade das massas é refreada pela ordem imposta pelo Estado moderno.

$M$ as não podemos negligenciar que 0 advento do Estado moderno se faz em um contexto marcado pelo desenvolvimento do capitalismo. 0 modo defuncionamento próprio do capital se expressa na maneira como o Estado moderno opera. 0 capital como princípio de equivalência universal confere à modernidade um caráter de totalidade, universalidade e de mundialização. 0 coletivo se submete ao imperativo da unidade do capital. É neste sentido que a massa se transforma numa totalidade ordenada por um princípio de equalização da existência, ao mesmo tempo em que se faz representar na unidade/totalidade do Estado. 0 capitalismo, portanto, é indispensável para a transcendentalização do governo político, isto é, para a organização de um Estado representativo moderno. A soberania ganha estatuto universal e transcendental, estendendo-se sobre todo o socius com seu poder de regulamentação como biopolítica da espécie humana que, na segunda metade do século 18 , vem complexificar o plano político não mais exclusivamente se dando na forma de uma anatomopolítica dos corpos dóceis (Foucault, 1999). 0 queFoucault nos indica é que o projeto político da modernidade se monta a partir de uma dupla focalização: nos corpos individuados, docilizados para seu melhor aproveitamento pelos apareIhos de produção e na população que se torna 0 alvo de práticas extensivas de controle.

Quando acompanhamos a construção deste projeto político no século 18 esta dupla focalidade exige uma função-relé que permite que as práticas de poder possam ampliar o jogo de assujeitamento incidindo ora sobre os indivíduos, ora sobre as populações. Deve-se destacar que é também a partir de pesquisas que Foucault faz com os textos históricos acerca das modulações das práticas de saúde que sua analítica se constrói. N este sentido, as práticas de cuidado médico no século 18 ganham uma importância na articulação do que é do domínio do privado e do domínio do coletivo. É uma nosopolítica refletida (Foucault, 1979d), posto que é uma nova preocupação com o tema da doença que explicita, na discursividade e nas tecnologias de cuidado, regras de controle da população e de cuidado com os indivíduos. Tais práticas de poder, que como assinalou Foucault, são distribuídas em todo corpo social sem nenhum lugar privilegiado de emergência, mantêm com o Estado moderno uma relação particular colocando-o como gestor da saúde da população.

A dimensão de omnicontrole que Foucault designou como biopoder faz com que o Estado desempenhe cada vez mais uma função policial. Esta função persiste no percurso, que vai da inauguração do Estado moderno à atualidade, mesmo quando nos vemos confrontados com uma expressiva alteração, em nível mundial do papel do Estado como formulador das políticas nacionais. Observamos especialmente nas últimas quatro décadas a reorganização minimal do Estado num cenário de globalização transnacional do capitalismo, em que mecanismos de controle dos indivíduos e populações tornaram-se cada vez mais distribuídos e 
não localizados. No entanto, em países como 0 Brasil, onde o Estado de bem-estar social sequer chegou a se concretizar, a relação entre as políticas públicas e o Estado, no seu papel regulamentador, não pode ser negligenciada. No que se refere ao campo da saúde no Brasil, o movimento sanitário e a constituição do SUS acontecem em anos onde o neoliberalismo cresce. Neste sentido, o SUS como política de Estado foi certamente uma forma de resistência a essa tendência mundial. $M$ as reconhecer a importância dessa conquista não pode significar um afastar-se do que está em sua base, a saber, a força emancipatória do movimento constituinte do SUS. Cabe, então, perguntar como manter esta força constituinte quando estamos comprometidos com a humanização da saúde como uma política pública, uma política coletiva. Qual o papel dos coletivos em sua relação com o Estado? Que conceito de humano se forja neste processo de controle das massas realizado pelo Estado?

Diante das massas movidas por impulsos irracionais, o Estado moderno se fundou por uma contratualidade que as protege de seu próprio movimento. É porque se pressupõe que as massas são perigosas que se convoca o cidadão a firmar um contrato social a partir do qual ele cede poder a uma instância transcendental que o representa. Esta instância assume, doravante, o papel de controle político-econômico, isto é, controle da cidade (polis) e controle das famílias e das populações (eicos). Tal controle se exerce - e esta é outra importante indicação de Foucault - por um Estado representativo e policial. 0 Estado policial tem a tarefa de controle das massas ou de gestão do corpo social. Foucault, assim, retoma e retorce o conceito de Estado de polícia formulado originalmente por historiadores constitucionais alemães do século 19 que, movidos pelo ideário liberal burguês, defendiam o ideal constitucional do Estado de direito. 0 termo alemão Politzei diz respeito a uma prática de gestão da população buscando a "integração acessória" dos indivíduos ao Estado (Foucault, 2004). Paradoxalmente na racionalidade política do Estado moderno comparece um duplo movimento: de individualização e integração à totalidade do Estado. Foucault designa este movimento de tecnologia política dos indivíduos que produz homens ativos e produtivos para a ordem social. Dessa forma, a relação entre Estado e individuação ganha aqui um sentido de assujeitamento que precisa ser colocado em análise quando estados às voltas com a construção de uma política de humanização.

Cabenos, agora, perguntar qual éa posição do sujeito na composição das massas. Pode-se verificar a ligação e simultaneidade da teoria moderna do homem como sujeito e o Estado de polícia. Descartes é um representante dessa modernidade que definiu o homem separando corpo e alma, o que se articula com esta outra separação entre estado natural e estado civil, entre paixão e razão. A operação moderna no seu afã purificador distingue e separa os termos e, mais do que isso, submete o primeiro ao segundo termo de cada oposição. N este sentido, tudo se submete aos imperativos da racionalidade, do contrato social, de tal maneira que, na modernidade, os direitos se assentam menos na experiência do homem e mais no contrato que assegura o controle social.

É neste sentido que uma autora como Barret-Krigel (1988) afirma a incompatibilidade entre o Estado moderno com sua função policial e os direitos humanos, como direito que salvaguarda a experiência de cada homem e de qualquer um. A teoria do homem como sujeito da razão separado das paixões e dos embates entre os corpos, separado da natureza como plano comum da existência, pode fundar uma doutrina de direitos civis e se harmonizar com um Estado administrativo-policial, mas não pode estar de acordo com os direitos humanos. A doutrina dos direitos humanos supõe uma teoria do homem diferente desta que separa o homem da natureza através dos mecanismos do contrato social e da representação política. Estes mecanismos estão diretamente associados à criação do fundamento da sociedade moderna: o H omem como figura ideal e o Estado$\mathrm{N}$ ação como figura gerencial. Tal fundamento pressupõe o movimento reflexivo segundo 0 qual o Sujeito em sua transcendência se constitui ao mesmo tempo como base do humano e em defasagem com a sua natureza ou corporeidade. $\mathrm{Na}$ experiência de uma defasagem interior - como aquela entre corpo e espírito, entre o Homem e um homem - o sujeito se constitui como fundamento do humano e do que, de direito, é o Homem e a organização da sociedade. No entanto, este "de direito" nunca se concilia com o que é de fato a experiência de um homem.

É a partir da idéia transcendente do Homem que o campo do direito burguês se organiza de modo fragmentado e por binarismos em que os termos se distinguem e se separam. 
0 direito se encontra parcelarizado, dividido penal, público, civil, administrativo - , sendo os direitos do homem recusados e/ ou marginalizados por esta divisão do campo do direito. Segundo o comentário de Barret-Kriegel, o desenvolvimento do Estado de polícia coincidiu com a preferência pela segurança da sociedade. N este caso, não é que Foucault tenha desconsiderado, em sua descrição da polícia, o direito, mas é que ele observou as formas exatas através das quais o direito, tornado norma, se metamorfoseou em prática de pretensa "defesa da sociedade" em nome do que os direitos de um homem ficam sempre referidos e mesmo submetidos ao direito do Homem, esta figura reguladora do socius.

Este ideal transcendente, portanto, opera formatando a realidade a partir de um padrão nunca efetivado, mas que se impõe como promessa ou ideal a ser alcançado. N este sentido, 0 direito é menos uma efetividade do que um porvir ou uma finalidade.

Em contraste com esta idealização do direito que equivale a uma idealização do $\mathrm{H}$ omem, o desafio no contemporâneo é o de pensar 0 direito num plano comum, isto é, o direito construído na experiência concreta dos homens ou de um homem qualquer. Falamos, então, de um direito não idealizado, porque construído na jurisprudência ou na experiência concreta das lutas pelo direito. E se falamos de luta, não queremos, ao desidealizar o campo do direito, fazer movimentos que pudessem incorrer na barbárie. É certo que uma das maneiras de se proteger dos perigos do "direito do mais forte" é pela via de um Estado-gestor do contrato social. Entretanto, o que temos observado, passados dois séculos de instauração do Estado moderno é que os mecanismos de representação no campo político não têm dado conta da articulação dos direitos humanos com a dimensão humana das políticas públicas de saúde. Este Estado-gestor do contrato social se exerce e se legitima a partir da autoridade de uma instância superior, transcendental, separada da realidade concreta. Esta separação é uma operação de transcendentalização, operação através da qual a dimensão da política pública se submete ao Estado e um homem se submete ao Homem.

$\mathrm{Na}$ modernidade, a morte de $\mathrm{D}$ eus significou, na contra-revolução, a eleição do H omem como figura do fundamento transcendental. I ronicamente, é pelo pressuposto de uma dimensão transcendental do humano que o ho- mem, ele mesmo, é assujeitado. Libertar o humano torna-se, paradoxalmente, uma resistência ao H omem, ou à estratégia de sua morte. 0 homicídio em questão aqui é aquele que subverte o H omem como metro padrão ou idealidade a partir da qual se modela a existência humana. Tal metro padrão, por definição, está descolado da realidade sobre a qual ele se aplica. $\mathrm{Na}$ qualidade de figura transcendental que paira como realidade separada, o Homem é a garantia da normalização, da classificação e da definição de práticas modeladoras e corretivas de tudo que se afasta ou se desvia dessa figura identificatória ideal.

Este desvio desidentificatório, entretanto, não implica 0 abandono das utopias ativas. Distinguir utopia de idealidade é a condição para pensarmos outros princípios ou rumos de organização das instituições. A postamos no trabalho democrático pela via de sujeitos e coletivos protagonistas e co-responsáveis por sua própria história. A democratização institucional exige um reposicionamento dos sujeitos na experiência concreta de produção da realidade. Tal reposicionamento coincide com aquele que desloca, no debate acerca da humanização, 0 privilégio de ações orientadas por uma noção idealizada do Homem para aquelas comprometidas com a experiência singular de qualquer homem - um homem em processo contínuo de humanização. Estamos, então, diante de um novo humanismo. Humanização da saúde: por um novo humanismo

É na dimensão da experiência concreta que encontramos um "SUS que dá certo". A construção da PNH se fez por um "reencantamento do concreto" (Varela, 2003) enão a partir da definição de um modelo ou de um padrão-ideal para organização dos modos de atenção e de gestão no campo da saúde pública brasileira. No concreto da experiência da saúde pública pudemos encontrar a dimensão coletiva do processo de produção de sujeitos autônomos e protagonistas na produção de sua saúde. Neste sentido, em 2004 foi criado o Prêmio David Capistrano que recebeu num período de dois meses 671 inscrições de experiências criativas e inovadoras no campo da saúde pública. Este prêmio foi a oportunidade para a publicização de iniciativas, com significativa participação de usuários, trabal hadores e gestores, que apontavam para a construção de um SUS humanizado. Este panorama nacional do SUS, que o Prêmio deu relevo, já vinha sendo acompanhado por consultores e técnicos da PNH que garantiam uma 
efetiva capilarização na ponta do Sistema. É neste sentido que a PNH invertia a tendência à interiorização própria da máquina do Estado apontando para estas linhas que vêm de fora do Estado nele inoculando a força do coletivo.

Se em 2003 construímos as bases da política, em 2004 foi possível ampliar significativamente seu raio de ação desenvolvendo um intenso processo de discussões e pactuações no âmbito dos Estados, municípios e serviços. Através de dispositivos, tais como os Grupos de Trabalho de Humanização, as O ficinas e atividades de apoio institucional, entre outros, a $\mathrm{PNH}$ se capilarizava resistindo às habituais determinações verticais e normalizadoras do MS. Essas ações eram acompanhadas da elaboração de conceitos e criação de subsídios práticos que davam suporte às intervenções.

Falar de saúde como processo de produção é falar de uma experiência que não se reduz ao binômio queixa-conduta já que aponta para a multiplicidade de determinantes da saúdee para a complexidade das relações entre os sujeitos trabalhadores, gestores e usuários dos serviços de saúde. 0 que se produz neste processo é a um só tempo a saúde e os sujeitos aí implicados. Por isso, falamos da humanização do SUS como processo de subjetivação que se efetiva com a alteração dos modelos de atenção e de gestão em saúde, isto é, novos sujeitos implicados em novas práticas de saúde. Pensar a saúde como experiência de criação de si e de modos de viver é tomar a vida em seu movimento de produção de normas e não de assujeitamento a elas. A contribuição de CanguiIhem (1978) para o debate acerca da normatividade da vida é indispensável. Este autor nos indicou como a vida se define não por uma assujeitamento a normas e sim por uma produção delas. A distinção proposta entre normalidade e normatividade dá a direção para este debate acerca do tema da humanização como experiência concreta de um homem em processo de produção de si e de sua saúde. Por humanização entendemos, portanto, menos a retomada ou revalorização da imagem idealizada do Homem emais a incitação a um processo de produção de novos territórios existenciais.

Dizíamos que malgrado o fato de a máquina de Estado tendencial mente dobrar para dentro as linhas de capilarização do poder, há sempre um lado de fora do que se dobra. Este fora que insiste no interior da máquina do Estado é o plano do coletivo, aí onde a política se consolida como experiência pública ou res pública.
M as criar novas práticas de saúde, mudar os modelos de atenção e de gestão do processo de trabalho em saúde é apostar em políticas públicas que vão se construindo numa estranha e paradoxal relação com a máquina do Estado. O paradoxo éo do funcionamento de uma máquina dita republicana que, no entanto, experimenta uma relação de tensão ou mesmo de repulsão diante da coisa pública. Eis a questão da qual não podemos nos furtar: o funcionamento de uma máquina Estatal em que a res pública está nela e contra ela.

Entendendo este fora do Estado como o plano do coletivo em que a saúde se apresenta como uma questão pública (uma res publica), apostar na humanização das práticas de saúde impõe, portanto, que repensemos a relação entre Estado e política pública. Quando esses dois termos não são mais tomados como coincidentes, quando o domínio do Estado e o do público não mais se justapõem, não podemos aceitar como dada a relação entre el es. Se o público diz respeito à experiência concreta dos coletivos, ele está em um plano diferente daquele do Estado como figura da transcendência moderna. O plano do público é aquele construído a partir das experiências de cada homem. Humanizar as práticas de atenção e gestão em saúde foi para a PNH levar em conta a humanidade como força coletiva que impulsiona e direciona o movimento das políticas públicas. N este sentido, não havendo uma imagem definitiva e ideal do Homem, só nos resta aceitar a tarefa sempre inconclusa da reinvenção de nossa humanidade, o que não pode se fazer sem o trabal ho também constante da produção de outros modos de vida, de novas práticas de saúde. Este trabalho só o fazemos, ou pelo menos só garantimos a ele sua máxima consistência, quando nos organizamos col etivamente em movimentos de resistência ao já dado, como assistimos no processo constituinte do SUS ou na proposta/aposta da PNH. É preciso manter vivo este processo afirmando o seu não esgotamento. 0 fato de o SUS ter se constituído como um texto legal, sua dimensão "de direito", não pode esgotar o que na experiência concreta se dá como o movimento constituinte e contínuo da reinvenção do próprio SUS. 


\section{Colaboradores}

O trabalho de elaboração do artigo foi desenvolvido de forma conjunta por $\mathrm{R}$ Benevides e $\mathrm{E}$ Passos.

\section{Referências bibliográficas}

Barret-kriegel B 1988. M ichel Foucault et l'État de police, pp. 222-229. In M ichel Foucault philosophe. Rencontre internationale. Seuil, Paris.

Benevides BR \& Passos E 2000. A construção do plano da clínica e o conceito de transdisciplinaridade. Psicologia: Teoria e Pesquisa. Brasília 16(1):71-80.

Brasil 2004. Política N acional de H umanização. Documento base para gestores e trabalhadores do SU S. M inistério da Saúde, Brasília.

Campos GWS 2000. U m método para análise e co-gestão de coletivos - a construção do sujeito, a produção de valor de uso e a democracia em instituições: o método da roda. Hucitec, São Paulo.

Canguilhem G 1978. $O$ normal e o patológico. Ed. Forense Universitária, Rio de Janeiro.

Foucault M 1977. Vigiar e punir. Ed. Vozes, Petrópolis.

Foucault M 1979a. Genealogia e poder, pp. 167-178. In R M achado (org.). M icrofísica do poder. Ed. Graal, São Paulo.

Foucault M 1979b. Soberania e disciplina, pp. 179-192. In R M achado (org.). M icrofísica do poder. Ed. Graal, São Paulo.

Foucault M 1979c. A governamentalidade, pp. 277-293. In R M achado (org.). M icrofísica do poder. Ed. Graal, São Paulo.
Foucault M 1979d. A política da saúde no século XVIII, pp. 193-207. In R M achado (org.). M icrofísica do poder. Ed. Graal, São Paulo.

Foucault M 1996. A verdade e as formas jurídicas. Ed. Nau, Rio de Janeiro.

Foucault M 1999. Em defesa da sociedade. Curso no Collège de France (1975-1976). Ed. M artins Fontes, São Paulo.

Foucault M 2000. 0 que são as luzes?, pp. 335-351. In M B M otta (org.) Ditos e escritos II. Ed. Forense Universitária, Rio de Janeiro-São Paulo.

Foucault M 2004. A tecnologia política dos indivíduos, pp. 301-318. In M B M otta (org.). Ditos e escritos VI. Ed. Forense Universitária, Rio de Janeiro-São Paulo.

Hardt M \& N egri A 2001. Império. Ed. Record, Rio de Janeiro.

Passos E \& Benevides BR 2001. Clínica e biopolítica na experiência do contemporâneo. Psicologia Clínica 13(1):89-100.

Varela F 2003. 0 reencantamento do concreto, pp. 33-52. In PP Pelbart \& R Costa (org.). Cadernos de subjetividade: o reencantamento do concreto. H ucitec, São Paulo.

Artigo apresentado em 11/03/2005 Aprovado em 6/04/2005

Versão final apresentada em 5/05/2005 